\title{
Seasonal variations in the nutritional status of urban Gambian children
}

\author{
BY A. M. TOMKINS, D. T. DUNN, R. J. HAYES AND A. K. BRADLEY \\ Medical Research Council Laboratories, The Gambia, and Department of Human \\ Nutrition and Tropical Epidemiology Unit, London School of Hygiene and Tropical \\ Medicine, Keppel Street, London WCIE $7 H T$
}

(Received 10 June 1986 - Accepted 22 June 1986)

1. Children aged 6-35 months in an urban community in The Gambia, West Africa, were weighed and their lengths measured at four surveys over an 18-month period, twice towards the end of the rains, and twice during the dry season.

2. Relative to international standards, height-for-age deteriorated steadily with age, while weight-for-age fell sharply in the second-half of infancy but showed no further deterioration from 12 to 35 months of age.

3. Height-for-age showed little seasonal variation, but weight-for-age and weight-for-height were lower at the end of the rains than during the dry season. Weight and height velocities were much lower during the rains than in the dry season, with more than $20 \%$ of the children losing weight during the rains. Possible reasons for these seasonal variations are discussed. Compensatory weight gain in the dry season exceeded the velocity expected from the standards in children aged 12 months or more, but height velocity fell below the standards all year.

4. The results are compared with previous findings from Keneba, a rural Gambian village. Weight velocity during the dry season was similar in the two communities, but the village children experienced a sharper decline in weight gain during the rains.

5. These results suggest that seasonal ecological factors may seriously influence the nutritional status of children living in an urban environment with adequate availability of food.

Malnutrition is a major problem in West Africa, and contributes to the severity of infectious diseases and child mortality in this region (McGregor et al. 1961; Tomkins, 1981). Previous studies in The Gambia have focussed on the prevalence of protein-energy malnutrition (PEM) among children living in Keneba, a rural village about $100 \mathrm{~km}$ from the Atlantic coast. These studies have indicated that height and weight velocities in this village are subject to dramatic seasonal variations, with a marked deterioration during the rainy season (Rowland et al. 1977). This pattern has been attributed to a number of ecological, cultural and economic factors. First, the incidence of infectious diseases, in particular malaria and diarrhoea, is higher during the rains, the increased incidence of diarrhoea resulting at least partly from the contamination during the rains of water supplies and the cereal gruels which form a major component of the children's diet (Barrell \& Rowland, 1979a). Second, there is a shortage of food at this time of year as stores from the previous year's harvest run out, and this may affect the energy available per child both directly, and indirectly through a reduced output of mothers' breast milk. Third, mothers have to spend much of their time during the rains on agricultural work in the fields, and the care and feeding of infants and young children is left to siblings and grandparents in the family compound.

Relatively little information is available on the nutritional status of children living in urban communities in West Africa, and for this reason studies have been conducted recently of children living in Bakau, an urban settlement on the Atlantic coast of The Gambia near the capital Banjul. Bakau has a cash economy, in contrast to Keneba which relies on subsistence farming, and at least some of the seasonal factors listed above are limited or absent in Bakau. There are no significant seasonal labour demands on the women of the community, and so the level of child care remains steady throughout the year. The availability and price of food, most of which is purchased from the local markets, show 
little seasonal variation. Water is chlorinated and obtained readily from standpipes, although it may become contaminated during storage in the compound.

Given these advantages, nutritional problems would be expected to be less common in Bakau than in rural Keneba, and seasonal fluctuations would be expected to be less marked. In the present study, the weights and lengths of children in Bakau were measured on four occasions over an 18-month period, at strategic points in the ecological calendar. The objectives were to describe the nutritional status and growth of these children relative to international standards, and to assess the extent of seasonal variation in these indices.

\section{METHODS}

The study was carried out in Bakau, an urban community with a population of about 10000 and an area of $0.7 \mathrm{~km}^{2}$. About two-thirds of the residents are recent migrants from rural areas of The Gambia or from other West African countries. A study of children in Bakau in 1982 (Pickering, 1984) showed that fathers' occupations included office and professional jobs $(28 \%)$, manual work $(39 \%)$ and a variety of self-employed jobs $(20 \%)$ including fishing, trading and taxi-driving, while $9 \%$ were unemployed and $4 \%$ were dead or living away from home. Occupations of the mothers included office and professional jobs $(6 \%)$, domestic service $(5 \%)$ and a variety of self-employed jobs $(15 \%)$ including trading and crafts. The remaining $73 \%$ of the mothers had no employment. Bakau has a cash economy, in contrast to Keneba which relies on subsistence farming. Thus rice was bought in the market in Bakau at government-controlled prices. It was readily available throughout the study period (Pickering, 1984) and there were no seasonal variations in availability of food or patterns of food preparation such as have been described in Keneba (Thompson, 1965). Housing ranges from European-style houses with flush toilets and mains electricity to traditional mud-brick dwellings often with little or no sanitation (Pickering, 1984). Health facilities include a local health centre providing curative and mother-and-child health services, in-patient and out-patient facilities at the nearby Medical Research Council (MRC) Laboratories, and a government hospital in Banjul. Almost all young children in Bakau have 'Road to Health' cards, giving accurate dates of birth.

In January 1981, a house-to-house survey of Bakau was undertaken and all residents were enumerated. Subsequently a registration system was established to ensure that all births, deaths and hospital admissions of children, and migrations in and out of the community, were recorded. Each child in Bakau was assigned an identification number which was transcribed on to the child's 'Road to Health' card, to facilitate the identification of the child and the linking of information collected on the child over a period of time.

Anthropometry surveys were carried out in May 1981, October 1981, February 1982 and September 1982. Survey 1 (May 1981) took place at the time of year when temperature and humidity start to rise as a prelude to the rains, which usually arrive in June. Surveys 2 and 4 (October 1981 and September 1982) took place towards the end of the rainy season, the last rains usually having fallen by the end of October. Survey 3 (February 1982) was conducted in the middle of the dry season which extends from November to May. It was considered to be important that the study should extend over two rainy seasons, as year-to-year variations may be substantial. Also it had been intended to conduct a further survey in May 1982, but this was precluded by administrative difficulties.

Before each survey, community meetings were arranged to discuss the plan of the study. Parents and guardians were invited to bring all children aged from 6 to 35 months to one of several conveniently-situated measuring sites. The homes of children who were eligible but who did not arrive for measurement were visited to encourage attendance the next day.

Children were weighed in light clothes, without shoes, using a Salter scale measuring to 
the nearest $100 \mathrm{~g}$. Supine length was measured using a wooden measuring board reading to the nearest $1 \mathrm{~mm}$. After measurement, each child was seen by a physician who treated minor ailments or referred the child to the local health centre, or to the out-patient clinic of the MRC Laboratories about $1 \mathrm{~km}$ away. All children also received $5 \mathrm{ml}$ piperazine elixir at each survey.

Using the NCHS growth standards (United States, Public Health Service, Health Resources Administration, 1977), based on the studies of children in the USA, the length and weight measurements were expressed as SD scores for height-for-age, weight-for-age and weight-for-height (World Health Organization, 1983). The standards for supine length were used throughout.

\section{RESULTS}

The average age of the children who were measured, and the coverage rates achieved at the four anthropometric surveys are shown in Table 1 . The average age was similar at all four surveys, and a detailed inspection of the age-distributions also indicated broad comparability. About $90 \%$ of eligible children were measured at the first survey, but the coverage rate declined to $76 \%$ at survey 2 and to even lower levels at surveys 3 and 4 . It is possible that our results have been distorted by selection bias, as the children who were missed at the later surveys may have had different growth characteristics from those who were measured. We believe any bias will have been slight, for two reasons. First, surveys 2 and 4 were conducted at the same time of year, towards the end of the rainy season. The nutritional status recorded at survey 2 (October 1981) with a coverage rate of $76 \%$, was very similar to that recorded at survey 4 (September 1982) with a lower coverage rate of $63 \%$. Second, a special analysis was performed to compare the height-for-age and weight-for-age at survey 1 of children who were seen subsequently at all later surveys ('regular' attenders) with those of children who missed at least one of the subsequent surveys ('irregular' attenders). There was little difference in height-for-age and weight-for-age between the regular and irregular attenders. We suggest that there is, therefore, unlikely to be a major selection bias.

Weight-for-age, height-for-age and weight-for-height at the four surveys are shown as mean SD scores in Fig. 1. Mean height-for-age declined steadily with age, from about -0.6 at $6-11$ months to almost $-2 \cdot 0$ at $30-35$ months of age, indicating that young children aged 6 months -3 years in this community gain height at a consistently slower rate than that expected from the international standards. There was little seasonal variation in attained height, as would be expected of a measurement which is not subject to short-term fluctuation. Weight-for-age and weight-for-height showed quite different patterns. Both indices showed a decline between the 6- to 11- and 12-to 17-month age-groups. Thereafter, weight-for-age remained fairly steady at around $-1 \cdot 2$, while weight-for-height increased again until it approached the level of the international standards by age 3 years. These findings indicate that children in Bakau put on much less weight than expected from international standards in the second-half of infancy and the first-half of the second year of life, but thereafter gain weight at roughly the expected rate. This, together with the continued deterioration in height-for-age, results in the distinctive $U$-shaped curve of weight-for-height. The fact that weight-for-height was close to the 'normal' level by 3 years of age shows that while these children were very short relative to international standards, they were not abnormally thin. Both weight-for-age and weight-for-height showed clear seasonal variation, being lower in all age-groups at the end of the rainy season (October 1981, September 1982) than during the dry season (May 1981, February 1982).

Results thus far have been presented as averages within age-groups, and give no insight 
Table 1. Achieved coverage and mean age at four anthropometry surveys in Bakau, The Gambia

\begin{tabular}{lcccc}
\hline Date... & May 1981 & October 1981 & February 1982 & September 1982 \\
\hline $\begin{array}{l}\text { No. of children } \\
\text { aged 6-36 months }\end{array}$ & 696 & 729 & 658 & 673 \\
$\begin{array}{l}\text { No. of children } \\
\text { measured }\end{array}$ & 624 & 551 & 401 & 427 \\
$\begin{array}{l}\text { Coverage (\%) } \\
\begin{array}{l}\text { Mean age (months) } \\
\text { of children measured }\end{array}\end{array}$ & 89.7 & 75.6 & 60.9 & 63.4 \\
\hline
\end{tabular}

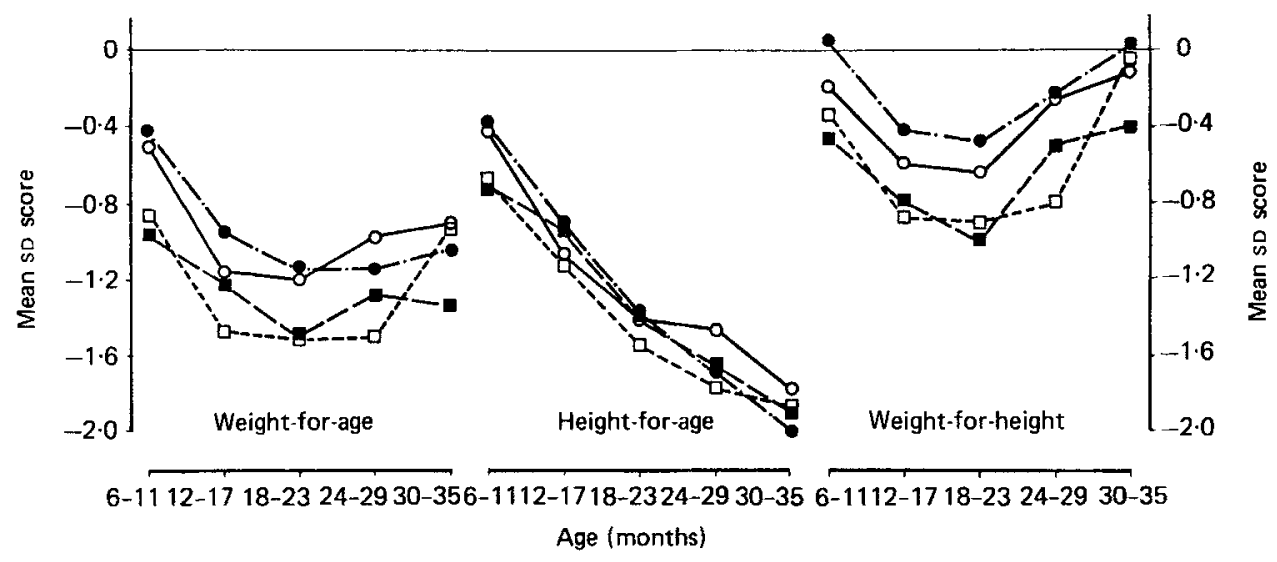

Fig. 1. Mean weight-for-age, height-for-age and weight-for-height by age-group and survey of urban Gambian children aged 0.5-3 years. (O), May 1981; (口), Oct. 1981; (O), Feb. 1982; (口), Sept. 1982.

into the variation between individuals. Fig. 2 shows the distribution of weight-for-height at each of the four surveys. The pooling of the age-groups was justified by the similar age-distributions at the four surveys. The reduction in mean weight-for-height at the end of the rainy season was due to a general shift of the distribution to lower values, and not to a small subpopulation of children who were very thin. Using an SD score of -2 or below to define 'wasting', the prevalences of wasting in Bakau were $5 \cdot 1,7 \cdot 8,3.9$ and $9.2 \%$ in May 1981, October 1981, February 1982 and September 1982 respectively.

Growth velocities provide a more dynamic measure of seasonal changes than attained growth. Fig. 3 shows the striking seasonal variation in weight velocity, Bakau children putting on weight at roughtly twice the rate during the dry season (October 1981 - February 1982 ) as in the rainy season (May 1981 - October 1981). From 12 months of age, weight velocity fell below the NCHS standards during the rains, but exceeded the standards during the first part of the dry season. This 'catch-up' growth explains why these children avoided a continuing deterioration of weight-for-age from the second year of life. In the second-half of infancy, however, weight velocity fell short of that expected from the standards even during the dry season. Height velocity (Fig. 4) exhibited similar seasonal changes, although less marked than those of weight velocity. Even during the dry season, however, when these children were gaining height most rapidly, height velocity failed to reach the NCHS norms. Figs. 5 and 6 show the individual variation in weight and height velocity. During the rainy 


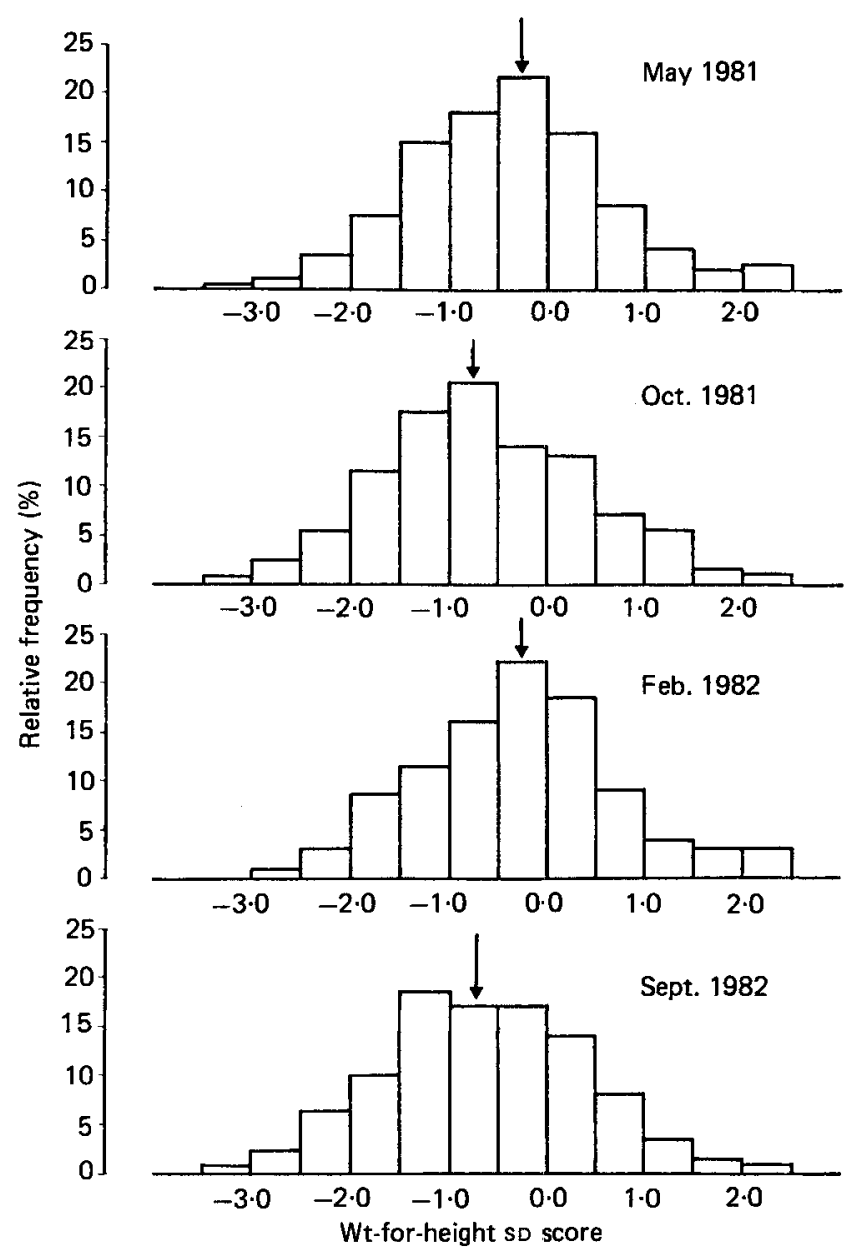

Fig. 2. Distribution of weight-for-height at each survey of urban Gambian children. For details of four surveys, see Table $1 . \downarrow$, Mean.

season (May 1981-October 1981), about 22\% of children in Bakau lost weight and only about $18 \%$ achieved weight gains in excess of $200 \mathrm{~g} / \mathrm{month}$ (roughly the average level expected from the NCHS standards from 12 months of age).

The results from our study of urban Bakau were compared with the findings of a study which took place in rural Keneba between May 1974 and October 1975 (Rowland et al. 1977). A group of 152 children aged between 0.6 and 3 years were weighed and measured at monthly intervals, and the average age at measurement ( $19 \cdot 2$ months) was similar to that in the Bakau study (Table 1). Attained weight curves for Bakau surveys 1 and 2, and for Keneba averaged over the period May 1974 - October 1975, are shown in Fig. 7. In Bakau, children of any given age were about $0.4 \mathrm{~kg}$ lighter in October 1981 at the end of the rains, than in May 1981. The children of Keneba, however, were considerably lighter and the differences became more marked with increasing age indicating a continuing deterioration in Keneba relative to Bakau. 


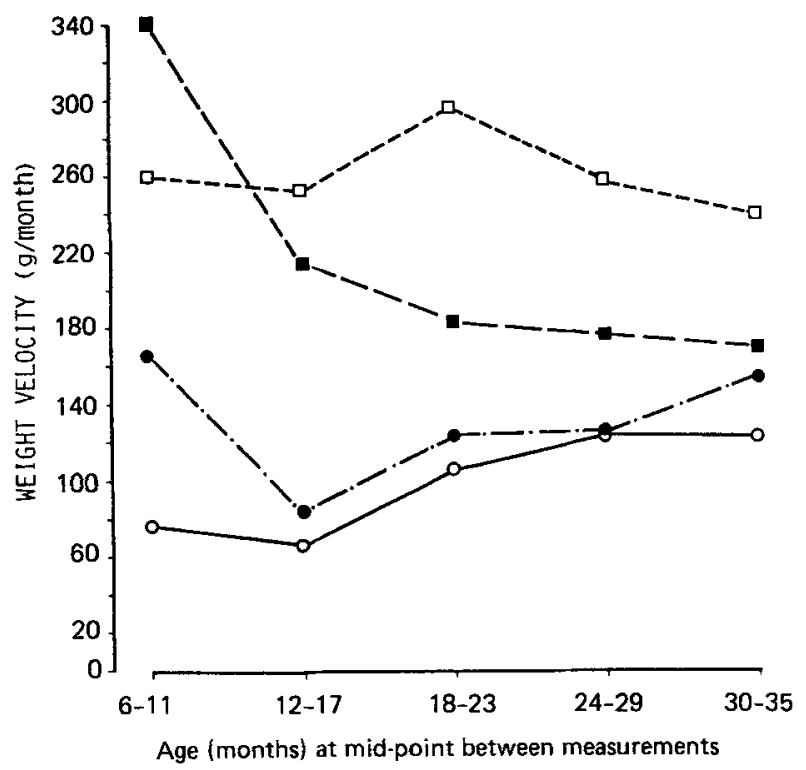

Fig. 3. Mean weight velocity between surveys by age-group for urban Gambian children aged 0-5-3 years. For details of surveys, see Table 1. (O), May-Oct. 1981; ( $\square$ ), Oct. 1981-Feb. 1982; (O), Feb.-Sept. 1982; ( $)$, reference velocity (NCHS; United States, Public Health Service, Health Resources Administration, 1977), sexes combined.

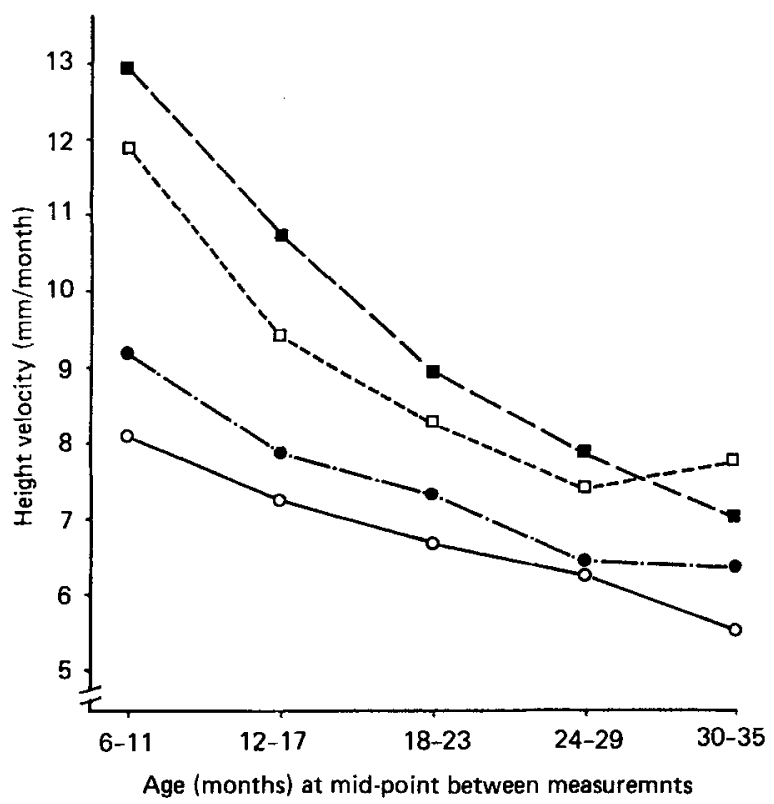

Fig. 4. Mean height velocity between surveys by age-group for urban Gambian children aged $0 \cdot 5-3$ years. For details of surveys, see Table 1. (O), May-Oct. 1981; (口), Oct. 1981 - Feb. 1982; (O), Feb.-Sept. 1982; (ם), expected velocity (NCHS; United States, Public Health Service, Health Resources Administration, 1977), sexes combined. 


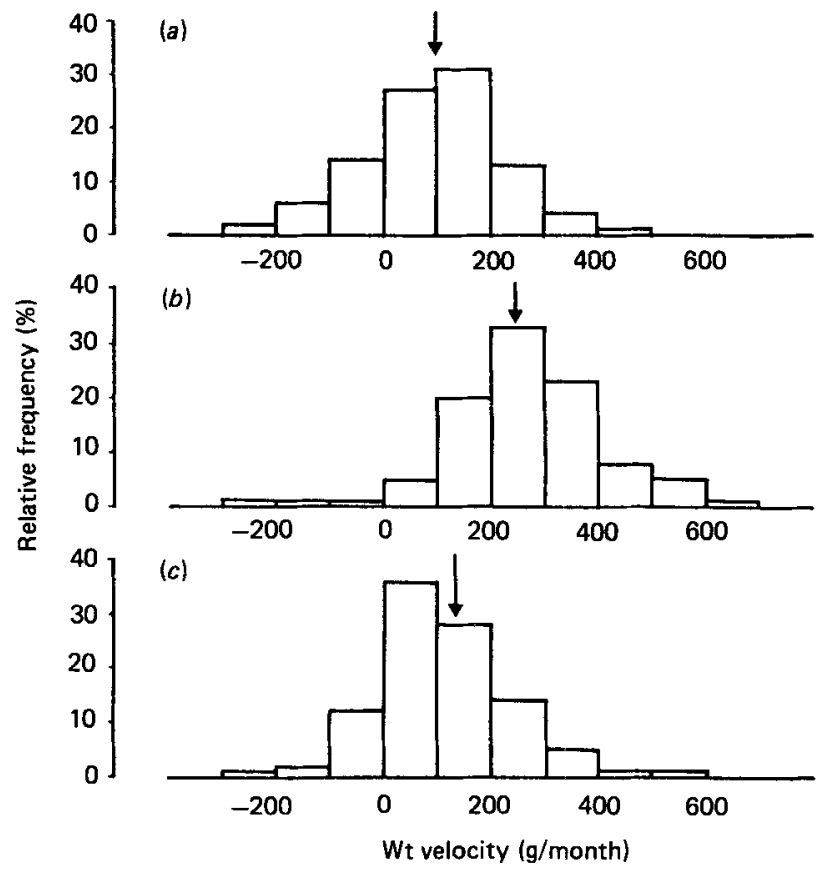

Fig. 5. Distribution of weight velocity between surveys of urban Gambian children aged 0.5-3 years. (a) May-Oct. 1981 ; (b) Oct. 1981 - Feb. 1982; (c) Feb.-Sept. 1982; $\downarrow$ mean.
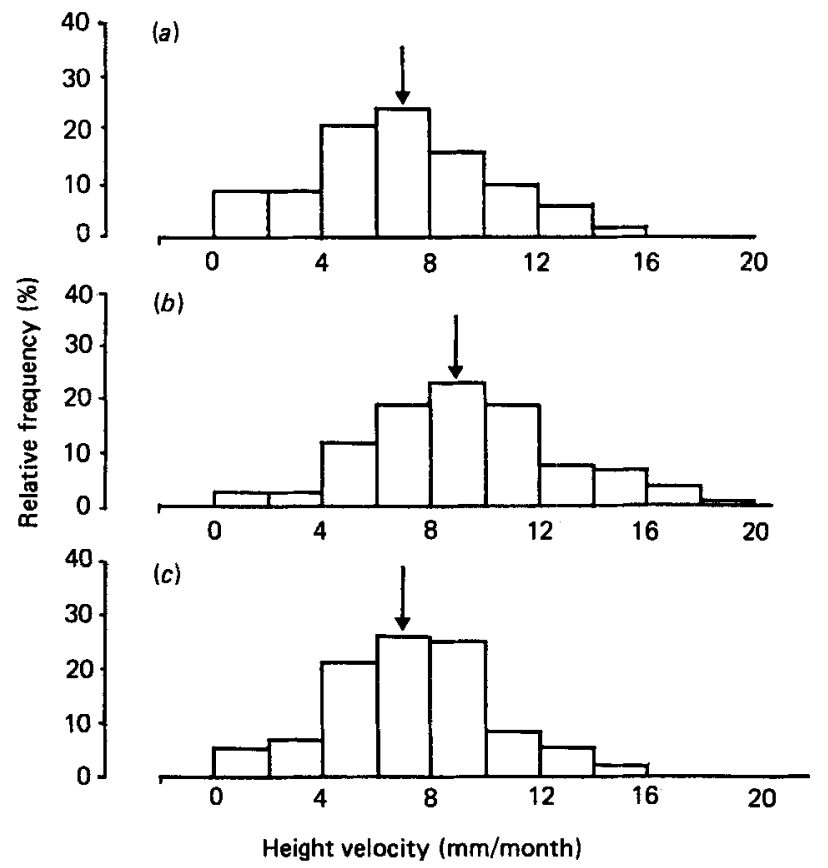

Fig. 6. Distribution of height velocity between surveys of urban Gambian children aged 0.5-3 years. (a) May-Oct. 1981; (b) Oct. 1981 - Feb. 1982; (c) Feb.-Sept. 1982; $\downarrow$ mean. 


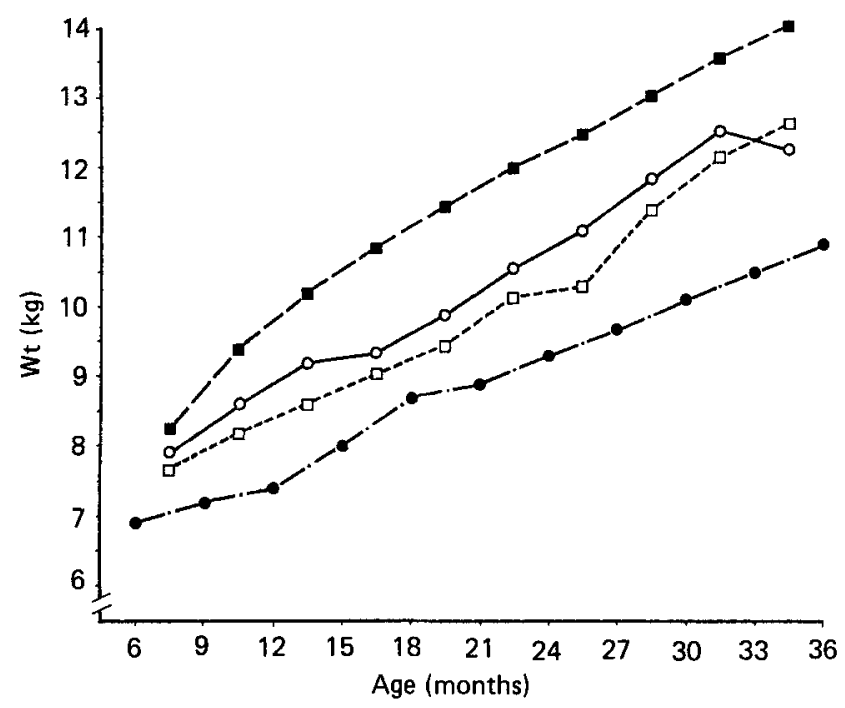

Fig. 7. Relation between weight and age of children in Keneba and Bakau (before and after rains) and NCHS (United States, Public Health Service, Health Resources Administration, 1977). (ロ), NCHS median (sexes combined); (O), Bakau, May 1981; ( $\square$ ), Bakau, Oct. 1981;(O), Keneba, averaged over May 1974 - Oct. 1975.

Table 2. Mean weight velocities in children aged $0.6-3$ years in Keneba (1974-5) and 0.5-3 years in Bakau (1981-2)

\begin{tabular}{lccc}
\hline Period... & May-October & October-February & February-September \\
\hline Keneba & & & 1975 \\
$\quad$ Year & 1974 & $1974-5$ & 70 \\
Mean wt velocity (g/month) & 15 & 243 & 1982 \\
Bakau & 1981 & $1981-2$ & 117 \\
Year & 95 & 264 & \\
Mean wt velocity (g/month) & & & \\
\hline
\end{tabular}

Weight velocities in the Keneba study were given for 2 -monthly intervals. To permit a comparison with Bakau, velocities in Keneba have been derived (using weighted averages) for the periods May-October 1974, October 1974-February 1975, and FebruarySeptember 1975, corresponding to the three periods studied in Bakau in 1981-2. The results are shown in Table 2. There was little difference in weight velocity between Bakau and Keneba during the dry season (October-February). The decrease in velocity during the rains, however, was much more marked in Keneba, and average weight gain during the rains in this village was close to zero.

\section{DISCUSSION}

Our results on the nutritional status of young children in Bakau show that despite the advantages of an 'urban' life-style, with the general availability of electricity, potable water, adequate health care facilities and a steady food supply, the growth of these children was far from 'optimal' at least when assessed relative to the international standards. 
Height gain was consistently lower than expected from the international standards and by 3 years of age average height was about 2 sD below 'normal'. In other words, the average 3-year-old in Bakau lay on the 3rd percentile of the NCHS standards. Bakau children were also underweight, and this was due to the poor weight gain in the second-half of infancy and tie first part of the second year of life. From 18 months onwards, average weight gain was similar to that achieved by North American children, and there was no further deterioration in mean weight-for-age, which remained at about $-1 \cdot 2$ (or about $88 \%$ of expected). Because these children became increasingly stunted as they grew older, while continuing to put on weight at roughtly the 'normal' rate, by 3 years of age few of them were abnormally thin. Even at the end of the rains, only 8 or $9 \%$ of the children were 'wasted' using the criterion of a weight-for-height SD score below -2 .

The marked differences between the growth of children in less-developed countries and those in industrialized societies has led some workers to question the appropriateness of the international standards, which are based on measurements of children in the USA during the 1960s (United States, Public Health Service, Health Resources Administration, 1977). It has been suggested that genetic factors may be responsible, at least partly, for the slower rates of growth of children in less-developed countries. There is increasing evidence, however, that privileged children in such countries, who benefit from a varied and adequate diet, favourable living conditions and effective health care, achieve similar growth to those in industrialized countries (Habicht et al. 1974). This suggests that the reduced growth in less-privileged communities is due mainly to social, economic, cultural and environmental factors (Janes, 1974).

One of the most striking results of our study was the substantial seasonal variation in the growth of the Bakau children. Both weight and height gains were considerably lower during the rainy season, and a considerable number of children $(22 \%)$ lost weight over the 5 months from May to October 1981. This poor weight gain in the rains was compensated for by 'catch-up' growth during the dry season, when average weight velocity exceeded that expected from the standards except in the youngest children (6-11 months). Because of this 'catch-up' growth, the weight gain over the whole year in children over the age of 18 months was similar to that of North American children. Height gain was also faster in the dry season, but was still low relative to the standards, and this explains the continuing deterioration of height-for-age.

What factors are responsible for the poorer growth of Bakau children during the rainy season? Most families in Bakau have non-seasonal cash incomes, although a few may depend on seasonal employment, for example in the tourist hotels. Most food in Bakau is purchased in the markets, and although there were occasional shortages of particular items during the study period, supplies and prices were generally stable throughout the year. It therefore seems unlikely that poorer growth in the rains can be attributed to a shortage of food at this time of the year. Child care also remains relatively steady throughout the year, as there are no significant seasonal demands on the women of this community.

The increased incidence of infectious diseases during the rains is probably an important factor. Preliminary analysis of the prevalence of diarrhoea in a group of children who were visited regularly at home by field workers showed that during the period June-September 1981 there were on average $20 \%$ of children with diarrhoea on the day of the visit, compared with $14 \%$ of children with diarrhoea during the period October 1981-January 1982 (A. M. Tomkins, D. T. Dunn, R. J. Hayes and H. Pickering, unpublished results). Studies in Keneba (Rowland et al. 1977) showed a strong association between diarrhoeal and malarial morbidity, and impaired growth, and it is likely that there is a similar association in Bakau. Diarrhoea probably has the biggest overall effect, as the incidence of malaria is much lower and the duration of malarial attacks is limited by prompt treatment with 
chloroquine. Contaminated water and food may help to increase the incidence of diarrhoea during the rains (Barrell \& Rowland, 1979a). Water in Bakau is chlorinated and comes from standpipes, but may become contaminated during storage in the compounds, and there is also evidence of food contamination (Lloyd-Evans et al. 1984). The impact of diarrhoea on nutritional status is likely to be via a combination of anorexia, nutrient losses and possibly increased nutrient requirements.

Finally it is possible that general environmental features of the rainy season are more important than we think. The unpleasant climatic conditions during the rains probably cause irritability, interrupted sleep and tiredness, and it is possible that these lead to reduced appetite and food intake.

We cannot determine the relative importance of these factors, but it appears that they acted to reduce growth during the rains even in the youngest children under study (6-11 months). An important point to note is that the poorer growth during the rains in Bakau resulted from a general shift of the distribution to lower values, and not to a small subset of the population with very severe malnutrition.

Comparison of the children of urban Bakau with those of the rural village of Keneba produces some interesting results. First, the nutritional status of children in Bakau was considerably better than that in Keneba. At 9 months of age, Bakau children weighed on average, about $1 \mathrm{~kg}$ more than their Keneba counterparts, and the gap widened to about $2 \mathrm{~kg}$ by 3 years of age. Our results indicate that weight velocities in the dry season were fairly similar in the two communities, but that the velocity fell during the rains much more sharply in Keneba than in Bakau. This is presumably because additional factors operate in the rainy season in Keneba that do not apply in Bakua. First, Keneba is a village of subsistence agriculture, and food shortages generally develop during the rainy season as stores from the previous harvest run out. This may affect child growth directly through reduced intake of solid foods, or indirectly through poorer maternal nutrition resulting in reduced output of breast milk (Waterlow et al. 1980). Second, women in Keneba make a heavy contribution to agricultural work in the fields during the rainy season. This means that they are away from the home for much of the time, and the children are looked after by siblings or older family members. In some cases this may result in lower standards of child care. Third, Keneba does not have a piped supply of potable water, and it is possible that the well-water is more heavily contaminated with pathogens during the rains (Barrell $\&$ Rowland, $1979 \mathrm{~b}$ ). This may contribute to the heavy toll of diarrhoeal disease in Keneba during this season.

This comparison with findings from Keneba is subject to several reservations. First, the Keneba information was collected in 1974-5 and that from Bakau in 1981-2. Each of these surveys covered 2 calendar years only, and may not represent the usual pattern in these communities. It is possible, for example, that there are substantial year-to-year variations in child growth, due to varying rainfall and other factors, and that 1974 and 1975 were particularly poor years in Keneba. We cannot exclude this possibility, although rainfall values for Keneba suggest that these years were not untypical.

Second, the differences in the results from Bakau and Keneba may have arisen due to a gradual improvement in conditions in both communities during the intervening years between the two studies. Experienced workers, however, believe that there are unlikely to have been important changes since 1974 in the nutritional status of children living in rural areas of The Gambia, although there have been improvements in Keneba itself, probably as a result of various medical and nutritional interventions there.

Our findings suggest, therefore, that urban children in The Gambia grow better than rural children, but still fall far short of international growth standards. This is due to their poor growth in the rains, and we believe this results largely from the increased incidence of infectious diseases, particularly diarrhoea, during this season. 
The authors would like to thank the staff of the Medical Research Council Laboratories in The Gambia for their help during the collection and preliminary analysis of the data. We would also like to thank the staff of the Medical and Health Department of the Gambian Government, and in particular Drs Oldfield, N'jie and Gowers, for their helpful advice.

\section{REFERENCES}

Barrell, R. A. E. \& Rowland, M. G. M. (1979a). Transactions of the Royal Society of Tropical Medicine and Hygiene 73, 85-90.

Barrell, R. A. E. \& Rowland, M. G. M. (1979b). Journal of Hygiene, Cambridge 83, 143-150.

Habicht, J.-P., Martorell, R., Yarbrough, C., Malina, R. \& Klein, R. (1974). Lancet i, 611-615.

Janes, M. D. (1974). Tropical and Geographical Medicine 26, 389-398.

Lloyd-Evans, N., Pickering, H. A., Goh, S. G. J. \& Rowland, M. G. M. (1984). Transactions of the Royal Society of Tropical Medicine and Hygiene 78, 209-211.

McGregor, I. A., Billewicz, W. Z. \& Thomson, A. M. (1961). British Medical Journal ii, 1661-1666.

Pickering, H. (1984). Social and environmental factors associated with high rates of diarrhoea in young children. PhD Thesis, University of London.

Rowland, M. G. M., Cole, T. J. \& Whitehead, R. G. (1977). British Journal of Nutrition 37, 441-450.

Thompson, E. D. B. (1965). Marriage, childbirth and early childhood in a Gambian village. A socio-medical study. $\mathrm{PhD}$ Thesis, University of Aberdeen.

Tomkins, A. (1981). Lancet i, 861-862.

United States, Public Health Service, Health Resources Adminstration (1977). NCHS Growth Charts. Rockville, MD.

Waterlow, J. C., Ashworth, A. \& Griffiths, M. (1980). Lancet ii, 1176-1178.

World Health Organization (1983). Measuring Change in Nutritional Status: Guidelines for Assessing the Nutritional Impact of Supplementary Feeding Programmes for Vulnerable Groups. Geneva: WHO. 